\title{
Study of Creative Thinking in Digital Media Art Design Education
}

\author{
Wei Zhu \\ Graduate School of Design, Chosun University, Gwangju, Korea \\ Email: zhuwei11@163.com
}

How to cite this paper: Zhu, W. (2020). Study of Creative Thinking in Digital Media Art Design Education. Creative Education, $11,77-85$

https://doi.org/10.4236/ce.2020.112006

Received: January 2, 2020

Accepted: February 9, 2020

Published: February 12, 2020

Copyright (C) 2020 by author(s) and Scientific Research Publishing Inc. This work is licensed under the Creative Commons Attribution International License (CC BY 4.0).

http://creativecommons.org/licenses/by/4.0/

\begin{abstract}
In recent years, with the rapid development of the information age and the wide dissemination of information technology knowledge, the "Internet + micro era" has been created, and the diversified development of the art field has also been promoted at the same time. The difference between professional and traditional education in digital art design education is a great challenge and change that modern innovative education will face. In this context, digital media art design education is facing a phase of adjustment. Based on the current situation of digital media art design education, this paper analyzes the influence and existing problems of digital media art in contemporary art design education, including the confusion of teaching mode, the deficiency of knowledge construction system and the aging of course content. Finally, some countermeasures and suggestions are put forward from the perspective of innovative thinking education.
\end{abstract}

\section{Keywords}

Digital Media, Art Design Education, Creative Thinking

\section{Introduction}

The era promotes the reform of new art, and the emergence of digital media art drives the digitalization of the art field. As the new orientation of digital media art design education in the new era, new media, new art and new thinking have become the main force of culture, economy and art. In terms of higher education in art and design, professional development in China lags behind other countries. Digital media art teaching lacks scientific, standardized, unified teaching mode and means for professional scientific knowledge guidance planning. It is difficult for students to learn and study digital media art design by training only software technology in professional courses, which makes students' 
art design study into a dilemma. The slow updating speed of teaching equipment and software in various colleges and universities, the uneven professional level of teachers in digital media art design teaching, and the outdated teaching content and teaching methods lead to the lack of strong guarantee in the teaching process, which restricts the progress of digital media art design education $(\mathrm{Xu}$, 2014).

\section{The Current Situation of Digital Media Art Design Education}

Digital media art design education is an interdisciplinary subject combining Internet technology and artistic innovation. Following the pace of "Internet + micro era", the specialized courses of digital media art design education are gradually included in the field of education. Different from the traditional education art courses, the digital media art design education course is based on the market, and from the perspectives of production, learning and research, it cultivates the creative thinking, creative consciousness and operational ability of digital media art talents.

\subsection{Analysis from the Perspective of "Internet + Micro Era"}

Digital media art design education relies on the development of Internet technology. How to make better use of the network for effective teaching becomes the core of innovative thinking education, especially in the current "Internet + micro-era" network environment. In the formal classroom and informal classroom auxiliary learning, the creative thinking of art design should be practiced. Among them, the key direction of teaching tends to the design and management of network learning, as well as the intelligent management of network art design learning content. In recent years, through the evaluation of online learning projects, it is found that students' learning effect far exceeds that of traditional teaching. Therefore, the use of digital media equipment and network technology for transmission and dissemination, become the key to the development of innovative thinking in education.

\subsection{Analysis from the Artistic Design Expression Form}

The inspiration of art design comes from life, and the creative conception of artists is inseparable from the display of various corresponding arts in life. If students are not able to master and understand the rules and performance, characteristics and attributes, as well as the techniques of expression of creation, they will not be able to express their feelings and concepts for artistic works in digital media art design. Rodin once said, "if learning loses its volume and proportion, as well as its color, the hand of inspiration will also be lost and strong emotions will be paralyzed." Therefore, in digital media art design, the expression form of art design is related to the understanding of art, the cognition of art abstraction, and the aesthetic understanding of art. Only by continuous practice and training 
more talents in the field of digital media art design can more forms of artistic expression be created (Jin, 2010).

\section{The Influence and Problems of Digital Media Art in Contemporary Art Design Education}

\subsection{The Influence of Digital Media Art Design under Innovative Thinking on Art Education}

With the emergence of the field of digital media art design, contemporary art design education has also changed. First, the educational means of art design and the teaching concept have been changed. Digital media art design infuses modern and post-modern art concepts and pays more attention to the collaboration between technology and art. Secondly, the curriculum view has been changed. The introduction of technological frontier art resources as the reference topic of students' curriculum, art works are not only the creation of students in a certain form, personal expression of emotion and technical expression, but also the key to the connection between the creation and society. Finally, the change of students' learning methods extends from the creation in a single class to the online platform education, such as exhibition halls, interactive online art courses, online virtual art galleries, electronic picture albums and other places where students can create through various exhibition channels. Although teaching forms have been changed from the podium into the media lab, however, because digital media art design education in China lacks excellent creative thinking art education public resources, so more talent teams with digital media professional knowledge and technology and innovative thinking are needed to create, develop and manage art design education, therefore, digital media art design education will play a positive role in art education in the future.

\subsection{Problems in Digital Media Art Design Education under Innovative Thinking}

First, digital media art design classroom education model is in chaos. Because the current network education resources are too chaotic, the knowledge dissemination of art design professional level is uneven, many pieces of art knowledge fragments becomes garbage fragments, and more false information, violence information, rumor information and other resource information damage the learning spirit and judgment of art design students. Despite the fact that educational institutions have been sifting through online information and adopting a variety of educational models, students who are weak in independent learning will still be lost. In the past digital media art design education class, the school will make constraints on students' moral standards and teaching content to meet the support of art design education theory and digital media technology. However, schools often ignore students' restrictions on artistic creation and artistic free thinking imagination, and fail to create new sources of innovation. Therefore, the teaching application of the combination of science and technolo- 
gy mode and art education mode is the basis of cultivating new art talents under the innovative thinking in China (Wang, 2015).

Secondly, the knowledge system of digital media art design is insufficient and the innovative thinking is weak. Due to the lack of a sound knowledge system in digital media art design education, the creative thinking ability of art creation cannot go ahead. For example, traditional book teaching is sensory system teaching based on developing students' knowledge visual and artistic accomplishment. However, in order to make innovations in digital media art design education, it is necessary to strengthen students' sensory and listening functions and extend students' creative inspiration for art. The knowledge system related to digital media art design not only has a large span of knowledge, but also covers a wide range of knowledge, which leads to the inability to clarify the relationship between scientific and technological knowledge and art design in the teaching process, making student art design thinking too messy, forming thinking block effect, and as a result, students' professional knowledge and ability cannot improve.

Thirdly, digital media art design education curriculum content is aged. With the deepening of curriculum reform and the arrival of "Internet + micro era", art and design education will enter a new generation of e-books. Traditional paper books have been unable to meet the modern digital media teaching situation and teaching needs. At present, there are a large number of electronic books related to digital media art design education, and more and more art galleries and their exhibitions are conducted by Internet multimedia. From the perspective of media technology change, the digital media art design education form under the innovative thinking also needs to integrate sound, text, image, interaction and other integrated teaching modes, so as to achieve the timeliness, compatibility, sociality and dissemination of education. From the perspective of social form, digital media art design education with innovative thinking is the link between artistic creation and social culture.

\section{Innovative Measures of Digital Media Art Design Education under Innovative Thinking}

\subsection{Strengthen the Application of New Digital Media Software}

From the analysis of the development history of digital media, the birth and development of new digital media must not lack the contrast with traditional media, and the combination of its advantages and disadvantages for common development. At present, with the rise of mobile apps on the Internet, the second road of digital media art design teaching has been opened up. Digital book content is realized through a variety of mobile terminals, such as tailor-made readers, computers, PDA, CJA and other media forms that integrate the characteristics of traditional paper books. Today's electronic data will be influenced by the characteristics of media in terms of layout design, content selection of art 
courses, and audience positioning. Both IOS and android are free and open for source operating systems to develop high-performance applications for art design education. The computer-side art design software of the past has been gradually transferred to the mobile terminal equipment, and the education mode has been expanded from innovative logic thinking to divergent thinking. The simple and portable way enables students to interact with books in the learning process while APP software synchronizes the learning time fragments, improving students' practical manual and innovation ability, getting rid of the tangle of traditional textbook teaching knowledge, giving play to their appreciation of art and cultivating personalized learning needs.

\subsection{Accelerate the Improvement of Digital Media Mobile Devices}

The improvement of the mobile terminal of digital media art design education under the condition of the innovative thinking can change the diversified art elements into diversified art variable elements, which is also a significant change of digital media art design education. The mobile classroom can change the content of art courses from several traditional times to dozens of times of content exchange. In addition to completing repeated knowledge switching, it can also complete the integration of knowledge fragments, so that students can learn professional art design knowledge faster and more effectively. In the current 5G, 4 G, WIFI, GPRS and other mobile network support, combined with mobile devices to cut into the classroom learning tools, the course presentation effect is consistent. Because of the limitations of mobile terminal devices, it is suitable for learners to learn content with short time and small amount of knowledge when they are in a mobile learning environment. In addition, digital media mobile devices have interactivity, which can solve students' questions at any time and support various forms of communication and discussion. Students' discussions and researches make students' thoughts collide and reflect. It can also help students learn step by step, and realize the extension of digital media art design knowledge. The equipment records the data of students' learning process, which can also help teachers guide students' learning and help students improve the training direction of their professional knowledge (Wang, 2019).

\subsection{Strengthen the Innovation and Improvement of Curriculum and Teaching Mode}

The emergence of digital media technology has provided a new way for artistic design and creation, and art design works also become diversified because of the integration of digital media technology. From the depth of artistic content to the display of artistic achievements, the innovation of educational curriculum must be scientific, flexible and characteristic. Adjust the proportion of teaching and practice to cultivate students' comprehensive ability of art design. For example, the proportion of courses is arranged at $60 \%$, and the proportion of digital me- 
dia technology is arranged at $40 \%$. Teachers teach through the use of digital media techniques for artistic expression, put digital media technology and art throughout the teaching of art design in order to make students deeply understand that in the continuous development of the information age, excellent artistic creation works cannot do without the support of technology, and the performance of technology and art will also impact students' innovative thinking concepts and thinking patterns. So it is a wrong attitude to pay too much attention to one aspect of learning. In the actual digital media art design teaching, teachers should integrate the language of art design into digital media design, which can not only enable students to use computer technology to achieve a high level of creativity, but also enable students to design art works with high aesthetic value. In addition, in the process of learning art design software, students must master the skills and rules of learning digital media art design. The concept of any digital media art learning software is the same. Students are required to grasp and understand the application concepts and technical knowledge of the software as a whole, think and apply independently. The process from simple to complex technical operations should be gradual and refined. Students should use various digital media software tools flexibly to create different artistic effects. At the same time, teachers can use mobile terminals and online video and other apps to help students solve problems and technical problems in the creation process, so as to strengthen communication, interaction and discussion with students and improve the efficiency of learning digital media art design.

\subsection{Strengthen the Construction of Strength and Comprehensive Quality Training of Teachers}

The creative thinking in digital media art design education should be built in the teachers' team construction and the reasonable content of teachers' curriculum. Under the pressure of the new curriculum reform, teachers, as the soul of teaching, should not only broaden their horizons, but also enhance their own technical level and artistic aesthetic ability. The teaching contents and forms have a direct impact on students' interest in and degree of mastering knowledge. At present, with the rapid development of information technology and the full coverage of the Internet, digital media art design as one of the new professional disciplines in the field of art education, its teaching content not only needs to be synchronized with the current demand for art, but also needs to be synchronized with the market economy. Therefore, while making the teaching plan, teachers should also make changes according to the market economy, so as to have a keen insight into the development trend of art and keep up with the development of The Times to obtain the foreword information. Teachers should often organize students to discuss, study and explore art courses, provide students with a more scientific learning platform, stimulate students' interest and desire in learning, reasonably suggest students' learning direction and focus, and promote the professionalization of digital media art design to a new high. 


\subsection{Strengthen the Practicality of Digital Media Art Design Education}

Digital media art design is scientific and practical. The birth of design work must be built on the basis of professional technology to achieve the perfect combination of technology and art. An excellent art design work needs not only the innovation of cultural creativity, but also the combination of the practical application of digital media technology and artistic creation ideas. An artistic design work should be targeted, technical and practical. In addition, art colleges and universities can work with design projects from all walks of life to create training bases for practical practice, innovation and entrepreneurship, so that students can improve their digital media art design skills from these projects. At the same time, this kind of education model can better train students' excellent and skilled art production technology. Only by constantly breaking through and adapting to the needs of contemporary society and innovating the teaching curriculum system and form can the whole digital media art design education better promote the production of art and culture. The digital media art field not only realizes the culture innovation, but also impacts students' innovative thoughts (Jiang \& Zhang, 2018).

\subsection{Processing Can Be Applied to Digital Media Art Design Education}

Due to the fact that more and more digital media art courses are unable to leave the support of interactive technology and computer graphics technology, and Processing is written based on JAVA language, which is easy to learn and master in programming and reading, so it is very suitable for digital media art teaching.

\subsubsection{Graphic Design}

Compared with Photoshop, Core DRAW and other graphic processing software, Processing can make designers more flexible and free in the process of drawing 2D or 3D graphics in digital media art design education. It can also let the computer purposefully or randomly generate graphics according to the designer's idea, which greatly enriched the performance of visual arts. Figure 1 is a picture of dynamic whirlpool shape with strong visual beauty designed by the designer Robert Hodgin with Processing. Compared with graphic design software in the traditional teaching, this design method of modern code generating graphics, is easier to inspire the creator's artistic inspiration.

\subsubsection{Information Visualization Design}

By means of visual design, the abstract information image is presented in front of the public, so that the transmitted information is more clear and efficient. Through convenient file import, Processing carries out visual design and rendering of data, and completes the production of information graphics and visual charts. In Figure 2, the designer visualizes the flight data of north American aviation, rendering each flight data point of each aircraft onto a computer screen so 


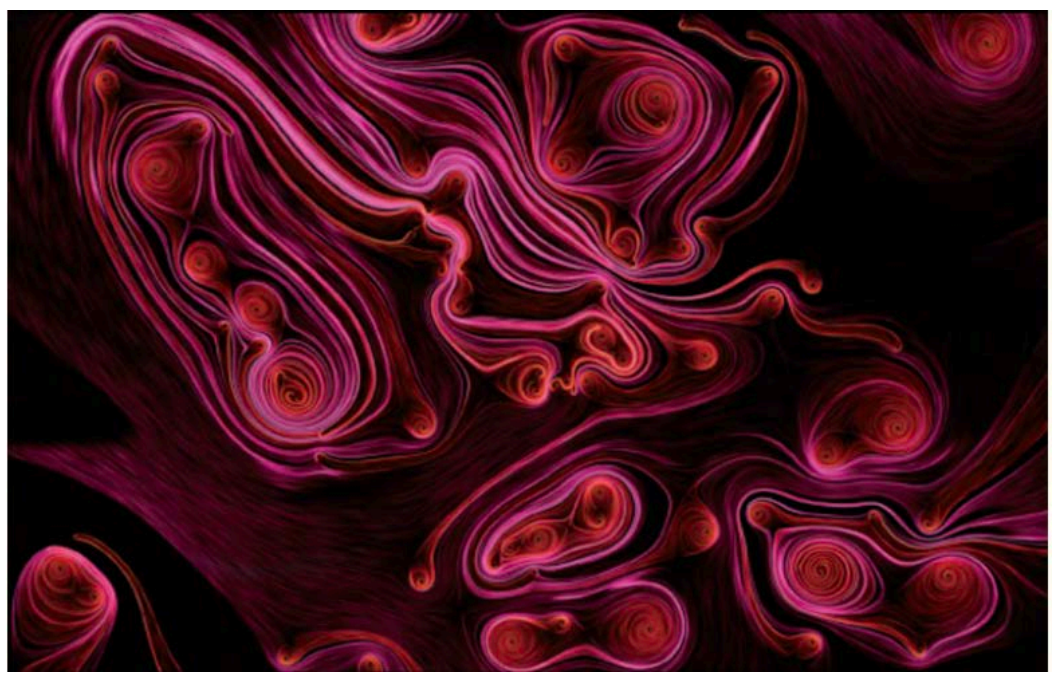

Figure 1. A picture of dynamic whirlpool shape designed with processing.

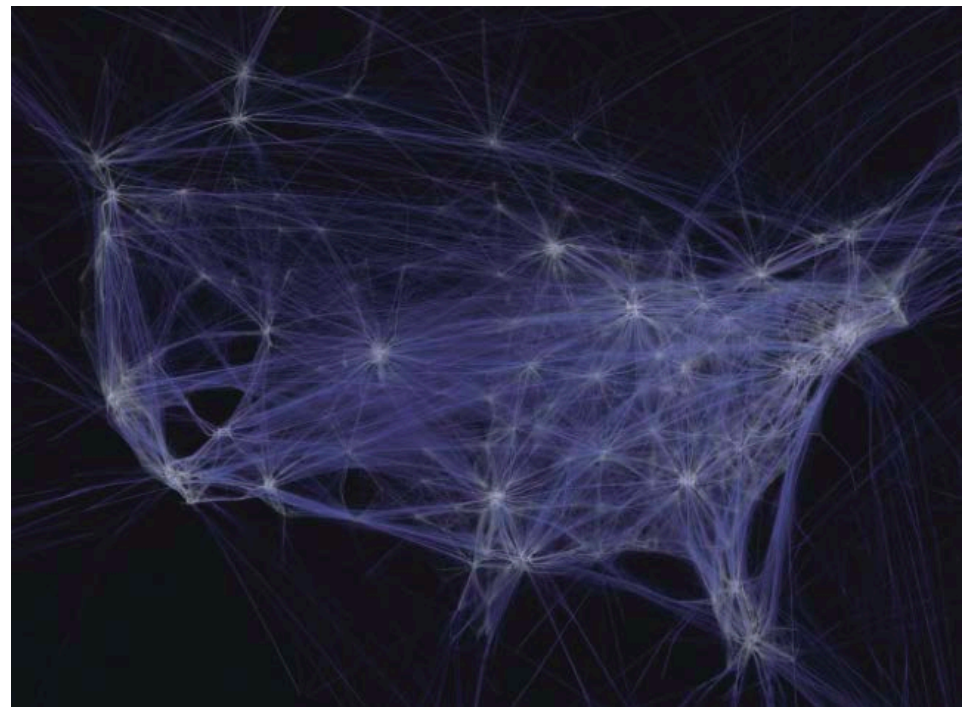

Figure 2. Flight data points of each aircraft onto a computer screen.

that people can clearly see the distribution (Brown, 2013).

\subsubsection{Simulation and Animation Design, and Interactive Installation Art Creation}

Processing not only realizes simulation calculation and engineering simulation through data import, but also realizes animation effect through the import of sequence graphics, and uses its own functions to complete $2 \mathrm{D}$ or $3 \mathrm{D}$ graphics animation rendering. Such animations add interactive actions or add random changes. When the mouse is activated by the audience, the animation will have movement and color changes to achieve interactive experience. API database can be used to realize the interaction with external equipment such as cameras. Sound sensors, light sensors and other input devices also can be used as input devices to achieve interaction. It can also produce interactive installation art works according to the needs of creators. It can promote the teaching of digital 
media art design and is a new way of artistic expression in the teaching of digital media art design.

\section{Conclusion}

To sum up, digital media art is the combination of science and technology and art industry. It uses a variety of technical means to create, produce, disseminate and sell art. And its consumption forms affect the development of culture and social economy; for example, animation art, film art, game art, photography art, digital music art and so on, have been integrated into people's lives. Therefore, the innovation of digital media art design education is imminent. At present, through the integration of Internet virtual classroom and offline classroom teaching, students use Internet devices to free up offline learning time, which lays a foundation for students to master digital media art design production technology. Internet information education mode is a kind of point-to-point knowledge dissemination with flexibility and high efficiency, which covers the global exchange of knowledge and breaks through the limitations of regional and traditional education models. At present, many Internet service providers provide free communication and information storage space for individuals, which enables students to collide with artistic design ideas and form innovative brainstorming, and also provide diversified learning modes for students.

\section{Conflicts of Interest}

The author declares no conflicts of interest regarding the publication of this paper.

\section{References}

Brown, J. W. (2013). A. V. Instruction; Technology and Media Methods. New York: McGraw-Hill.

Jiang, H. Y., \& Zhang, Y. T. (2018). Research on the Reform of Art Design Education Based on "Internet +". Home of Drama, 1, 1-3.

Jin, D. B. (2010). In the Internet Age, Newspapers Should Seek New Reporting Models. News Communication, No. 7, 13.

Wang, Y. X. (2019). Research on Innovative Thinking and Development Trend in Digital Media Art Design Education. Art Studies, 1, 1-15.

Wang, Z. M. (2015). A Brief Analysis on the Regional Characteristics of Digital Media Art Talent Training in Colleges and Universities in Western Hunan. Asia Pacific Journal of Education, 25, 7.

Xu. X. (2014). A Brief Analysis of Microage and Fragmented Survival. Nanjing: Nanjing Arts Institute. 